\title{
Clinicopathological features and prognosis of colonic gastrointestinal stromal tumors: evaluation of a pooled case series
}

\author{
Fan Feng ${ }^{1, *}$, Yangzi Tian ${ }^{2, *}$, Zhen Liu ${ }^{1, *}$, Guanghui $\mathrm{Xu}^{1}$, Shushang Liu ${ }^{1}$, Man Guo ${ }^{1}$, \\ Xiao Lian ${ }^{1}$, Daiming Fan ${ }^{1}$ and Hongwei Zhang ${ }^{1}$ \\ ${ }^{1}$ Department of Digestive Surgery, Xijing Hospital, Fourth Military Medical University, Xi'an, Shaanxi, China \\ 2 Department of Dermatology, Xijing Hospital, Fourth Military Medical University, Xi'an, Shaanxi, China \\ * These authors have contributed equally to this work \\ Correspondence to: Hongwei Zhang, email: zhanghwfmmu@126.com
}

Keywords: gastrointestinal stromal tumor, colon, feature, prognosis

Received: November 30, 2015 Accepted: April 16, $2016 \quad$ Published: May 05, 2016

\section{ABSTRACT}

Background: Due to the extremely rare incidence, data about colonic GISTs are limited. Therefore, aim of the present study was to explore clinicopathological characteristics and prognosis of colonic GISTs.

Patients and Methods: Colonic GISTs cases were obtained from our center and from case report and clinical studies extracted from MEDLINE. Clinicopathological features and survivals were analyzed.

Results: There were 79 colonic GISTs patients with a female predominance. The median age was 66 years (range 0.17-84). The median tumor size was $5.8 \mathrm{~cm}$ (range $0.5-29)$. The most common location was sigmoid colon $(45.8 \%)$, followed by transverse colon $(\mathbf{1 9 . 5 \% )}$. The majority of colonic GISTs were high risk $(\mathbf{7 0 . 8 \% )}$. Mitotic index was correlated with gender $(P=0.002)$ and tumor size $(P=0.005)$, and tumor location was correlated with age $(P=0.017)$. The five year DFS and DSS were $57.4 \%$ and $61.6 \%$, respectively. Mitotic index and NIH risk classification were associated with prognosis of colonic GISTs. However, mitotic index was the only independent risk factor. The distribution of tumor size and NIH risk classification were significantly different between colonic and gastric GISTs (both $P=0.000$ ). The DFS and DSS of colonic GISTs were significantly lower than that of gastric GISTs ( $P$ $=0.012$ and $P=0.002$, respectively).

Conclusions: The most common location for colonic GISTs was sigmoid colon. Most tumors were high risk. Mitotic index was the only independent risk factor for prognosis of colonic GISTs. Colonic GISTs differ significantly from gastric GISTs in respect to clinicopathological features. The prognosis of colonic GISTs was worse than that of gastric GISTs.

\section{INTRODUCTION}

Gastrointestinal stromal tumors (GISTs) are commonest mesenchymal neoplasm of alimentary tract, represent $1 \%$ to $2 \%$ of alimentary malignant tumors [1]. GISTs are derived from interstitial cells of Cajal (ICC), and are related with activating mutations in KIT protooncogene [2]. It has been established through positive staining for CD117 and CD34 [3]. Histologically, most GISTs show spindle morphology (70\%), followed by epithelioid (20\%) and mixed morphology (10\%) [4].

GISTs can occur anywhere in the alimentary tract but most commonly in the stomach $(40 \%$ to $70 \%)$ [5]. GISTs located in the colorectum are relatively rare, representing approximately $5 \%$ of all GISTs [6]. GISTs located in colon is much rarer, and it represents only 1-2\% of all cases [7]. Thus, studies involving large numbers of colonic GISTs are lacking, and the clinicopathological 
Table 1: Clinicopathological characteristics of 79 cases of colonic GISTs

\begin{tabular}{|c|c|c|}
\hline Characteristics & Number & Percentage \\
\hline \multicolumn{3}{|l|}{$\operatorname{Age}\left(\sum=75\right)$} \\
\hline$\leq 60$ & 33 & $44.0 \%$ \\
\hline$>60$ & 42 & $56.0 \%$ \\
\hline \multicolumn{3}{|l|}{ Gender $\left(\sum=75\right)$} \\
\hline Male & 34 & $43.0 \%$ \\
\hline Female & 41 & $57.0 \%$ \\
\hline \multicolumn{3}{|l|}{ Accompanied tumor $\left(\sum=64\right)$} \\
\hline GISTs with other locations & 8 & $12.5 \%$ \\
\hline Other manignant tumors & 3 & $4.7 \%$ \\
\hline \multicolumn{3}{|l|}{ Symptoms $\left(\sum=47\right)$} \\
\hline Abdominal pain & 16 & $34.0 \%$ \\
\hline Obstruction & 11 & $23.4 \%$ \\
\hline Bleeding & 11 & $23.4 \%$ \\
\hline Perforation & 7 & $13.9 \%$ \\
\hline Abdominal mass & 6 & $12.8 \%$ \\
\hline \multicolumn{3}{|l|}{ Location $\left(\sum=72\right)$} \\
\hline Cecum & 8 & $11.1 \%$ \\
\hline Ascending colon & 8 & $11.1 \%$ \\
\hline Transverse colon & 14 & $19.5 \%$ \\
\hline Descending colon & 9 & $12.5 \%$ \\
\hline Sigmoid colon & 33 & $45.8 \%$ \\
\hline \multicolumn{3}{|l|}{ Surgical resection $\left(\sum=72\right)$} \\
\hline Complete resection & 67 & $93.1 \%$ \\
\hline Incomplete resection & 4 & $5.5 \%$ \\
\hline No surgery & 1 & $1.4 \%$ \\
\hline \multicolumn{3}{|l|}{ Tumor $\operatorname{size}\left(\sum=69\right)$} \\
\hline$\leq 2 \mathrm{~cm}$ & 14 & $20.3 \%$ \\
\hline $2.1-5 \mathrm{~cm}$ & 17 & $24.6 \%$ \\
\hline $5.1-10 \mathrm{~cm}$ & 23 & $33.3 \%$ \\
\hline$>10 \mathrm{~cm}$ & 15 & $21.8 \%$ \\
\hline \multicolumn{3}{|l|}{ Mitotic index $\left(\sum=66\right)$} \\
\hline$\leq 5$ & 32 & $48.5 \%$ \\
\hline$>5$ & 34 & $51.5 \%$ \\
\hline \multicolumn{3}{|l|}{ Histological type $\left(\sum=56\right)$} \\
\hline Spindle & 49 & $87.5 \%$ \\
\hline Epithelioid & 3 & $5.4 \%$ \\
\hline Mixed & 4 & $7.1 \%$ \\
\hline \multicolumn{3}{|l|}{ Lymph node metastasis $\left(\sum=17\right)$} \\
\hline Yes & 3 & $17.6 \%$ \\
\hline No & 14 & $82.4 \%$ \\
\hline \multicolumn{3}{|l|}{ Immunohistochemisty } \\
\hline $\mathrm{CD} 117\left(\sum=58\right)$ & 48 & $82.8 \%$ \\
\hline $\mathrm{CD} 34\left(\sum=44\right)$ & 30 & $68.2 \%$ \\
\hline DOG- $1\left(\sum=6\right)$ & 4 & $66.7 \%$ \\
\hline \multicolumn{3}{|l|}{ Mutational status $\left(\sum=23\right)$} \\
\hline KIT exon 11 & 10 & $43.5 \%$ \\
\hline Others & 13 & $56.5 \%$ \\
\hline \multicolumn{3}{|l|}{ NIH risk category $\left(\sum=65\right)$} \\
\hline Very low risk & 12 & $18.4 \%$ \\
\hline Low risk & 7 & $10.8 \%$ \\
\hline Intermediate risk & 0 & $0 \%$ \\
\hline High risk & 46 & $70.8 \%$ \\
\hline \multicolumn{3}{|l|}{ Adjuvant therapy $\left(\sum=30\right)$} \\
\hline Yes & 8 & $26.7 \%$ \\
\hline No & 22 & $73.3 \%$ \\
\hline
\end{tabular}


Table 2: The relationship between clinicopathological characteristics

\begin{tabular}{|l|c|c|c|}
\hline Characteristics & Mitotic index( $\leq \mathbf{5})$ & Mitotic index(>5) & $\boldsymbol{P}$ value \\
\hline Gender & & & \\
\hline Male & $7(23.3 \%)$ & $20(62.5 \%)$ & 0.002 \\
\hline Female & $23(76.7 \%)$ & $12(37.5 \%)$ & \\
\hline Tumor size (cm) & & & \\
\hline$\leq 2$ & $10(32.3 \%)$ & $0(0 \%)$ & 0.005 \\
\hline $2.1-5$ & $7(22.5 \%)$ & $7(23.3 \%)$ & \\
\hline $5.1-10$ & $10(32.3 \%)$ & $13(43.4 \%)$ & \\
\hline$>10$ & $4(12.9 \%)$ & $10(33.3 \%)$ & \\
\hline & & & \\
\hline Tumor location & $\mathrm{Age} \leq 60$ & $\mathrm{Age}>60$ & \\
\hline Cecum & $3(10.0 \%)$ & $5(13.1 \%)$ & 0.017 \\
\hline Ascending & $3(10.0 \%)$ & $3(7.9 \%)$ & \\
\hline Transverse & $11(36.7 \%)$ & $2(5.3 \%)$ & \\
\hline Descending & $3(10.0 \%)$ & $6(15.8 \%)$ & \\
\hline Sigmoid & $10(33.3 \%)$ & $22(57.9 \%)$ & \\
\hline
\end{tabular}

Table 3: Survival data of $\mathbf{4 8}$ cases of colonic GISTs

\begin{tabular}{|l|c|}
\hline Survival characteristics & Parameter \\
\hline Follow up time & \\
\hline Mean(m, \pm SD) & $41.69 \pm 40.63$ \\
\hline Median(m, range) & $23.5(3-149)$ \\
\hline Survival data & \\
\hline Recurrence or metastasis & 15 \\
\hline GISTs related deaths & 18 \\
\hline Survival rates (\%) & \\
\hline 1-/3-/5-year DSS & $85.0 / 66.0 / 61.6$ \\
\hline 1-/3-/5-year DFS & $90.8 / 78.0 / 57.4$ \\
\hline
\end{tabular}

profiles and prognosis are limited. Therefore, the aim of our present study was to explore clinicopathological characteristics and prognosis of colonic GISTs.

\section{RESULTS}

The clinicopathological characteristics were summarized in Table 1. There were 34 male (43\%) and 41 female $(57 \%)$. The patient age ranged from $0.17-84$ years (mean, 60.9 years; median, 66 years). Eight patients accompanied with GISTs in other locations (12.5\%), including 2 cases with liver metastasis, 3 cases with peritoneal metastasis, 2 cases with rectal GIST and one case with jejunal GIST. Three patients accompanied with other malignant tumors $(4.7 \%)$, including 2 cases of ascending colon cancer and one case of endometrial carcinoma. The most common symptom was abdominal pain $(16 / 47,34.0 \%)$, followed by obstruction $(11 / 47$, $23.4 \%)$, bleeding $(11 / 47,23.4 \%)$, perforation (7/47, $13.9 \%$ ) and abdominal mass $(6 / 47,12.8 \%)$. The most common location was sigmoid colon $(33 / 72,45.8 \%)$, followed by transverse colon $(14 / 72,19.5 \%)$, descending colon $(9 / 72,12.5 \%)$, ascending colon $(8 / 72,11.1 \%)$ and cecum $(8 / 72,11.1 \%)$. Sixty-seven patients underwent complete surgical resection $(67 / 72,93.1 \%)$, four patients underwent palliative surgical resection (4/72, 5.5\%), and one patient treated with adjuvant imatinib therapy only $(1 / 72,1.4 \%)$.

Tumor size ranged from 0.5 to $29 \mathrm{~cm}$ in maximum diameter (mean, $6.5 \mathrm{~cm}$; median, $5.8 \mathrm{~cm}$ ). The mitotic index of 34 patients exceeded 5/50 HPF (34/66, 51.5\%). Forty-nine patients displayed spindle cell morphology (49/56, 87.5\%), three patients displayed epithelioid morphology $(3 / 56,5.4 \%)$ and four patients displayed mixed morphology $(4 / 56,7.1 \%)$. Among the 17 patients with lymph node dissection, 3 patients had lymph node metastasis $(3 / 17,17.6 \%)$. CD117 positivity was detected in 48 patients $(48 / 58,82.8 \%)$, CD34 positivity was detected in 30 patients $(30 / 44,68.2 \%)$ and DOG-1 positivity was detected in 4 patients $(4 / 6,66.7 \%)$. Twenty-three patients were analyzed for gene mutation status. Ten patients carrying a mutation in exon 11 of KIT $(10 / 23,43.5 \%)$. According to NIH risk classification, 12 patients were very low risk $(12 / 65,18.4 \%), 7$ patients were low risk $(7 / 65$, $10.8 \%$ ), no patient was intermediate risk, and 46 patients were high risk $(46 / 65,70.8 \%)$. Adjuvant imatinib therapy 
Table 4: Prognostic factors for DSS and DFS in patients with colonic GISTs according to univariate and multivariate analysis

\begin{tabular}{|c|c|c|c|c|c|c|}
\hline \multirow[b]{2}{*}{ Prognostic factors } & \multicolumn{3}{|c|}{ Univariate analysis } & \multicolumn{3}{|c|}{ Multivariate analysis } \\
\hline & $\boldsymbol{\beta}$ & $\begin{array}{c}\text { Hazard ratio } \\
(95 \% \text { CI })\end{array}$ & \begin{tabular}{|l|}
$P$ \\
value \\
\end{tabular} & $\boldsymbol{\beta}$ & $\begin{array}{c}\text { Hazard ratio } \\
(95 \% \mathrm{CI}) \\
\end{array}$ & $\begin{array}{l}P \\
\text { value } \\
\end{array}$ \\
\hline \multicolumn{7}{|l|}{$\operatorname{DSS}(n=48)$} \\
\hline Tumor size $(\leq 5 />5)$ & 1.34 & $\begin{array}{c}3.83 \\
(0.87-16.87)\end{array}$ & 0.076 & & & \\
\hline Mitotic index $(\leq 5 />5)$ & 2.06 & $\begin{array}{c}7.86 \\
(2.17-28.47)\end{array}$ & 0.002 & 2.01 & $\begin{array}{c}7.46 \\
(1.88-29.63)\end{array}$ & 0.004 \\
\hline NIH risk category $(1,2 / 4)$ & 3.44 & $\begin{array}{c}31.19 \\
(0.23-4308.01) \\
\end{array}$ & 0.024 & & & \\
\hline \multicolumn{7}{|l|}{ DFS $(n=48)$} \\
\hline Tumor size $(\leq 5 />5)$ & 0.43 & $\begin{array}{c}1.54 \\
(0.48-4.98) \\
\end{array}$ & 0.468 & & & \\
\hline Mitotic index $(\leq 5 />5)$ & 1.48 & $\begin{array}{c}4.40 \\
(1.38-14.00) \\
\end{array}$ & 0.012 & 1.43 & $\begin{array}{c}4.17 \\
(1.27-13.72) \\
\end{array}$ & 0.019 \\
\hline NIH risk category $(1,2 / 4)$ & 3.50 & $\begin{array}{c}32.96 \\
(0.17-6477.05)\end{array}$ & 0.031 & & & \\
\hline
\end{tabular}

Table 5: Comparison of selected clinicopathological parameters between colonic and gastric GISTs

\begin{tabular}{|l|c|c|c|}
\hline Characteristics & Colon $(\boldsymbol{n}=\mathbf{7 9})$ & Stomach $(\boldsymbol{n}=\mathbf{2 9 7})$ & $\boldsymbol{P}$ value \\
\hline Age & & & \\
\hline$\leq 60$ & 33 & 168 & 0.053 \\
\hline$>60$ & 42 & 129 & \\
\hline Gender & & & \\
\hline Male & 34 & 155 & 0.304 \\
\hline Female & 41 & 142 & \\
\hline Tumor size & & & \\
\hline$\leq 2 \mathrm{~cm}$ & 14 & 96 & 0.000 \\
\hline $2.1-5 \mathrm{~cm}$ & 17 & 107 & \\
\hline $5.1-10 \mathrm{~cm}$ & 23 & 72 & \\
\hline$>10 \mathrm{~cm}$ & 15 & 22 & \\
\hline Histological type & & & \\
\hline Spindle & 49 & 275 & 0.067 \\
\hline Epithelioid & 3 & 3 & \\
\hline Mixed & 4 & 19 & \\
\hline Mitotic index & & & \\
\hline$\leq 5$ & 32 & 163 & 0.346 \\
\hline$>5$ & 34 & 134 & \\
\hline NIH risk category & & & \\
\hline Very low risk & 12 & 58 & \\
\hline Low risk & 76 & & \\
\hline Intermediate risk & & & \\
\hline High risk & & & \\
\hline
\end{tabular}

were recorded in 30 patients, and 8 patients $(26.7 \%)$ received imatinib therapy. Among them, one patient received imatinib therapy after biopsy, the remaining 7 patients received imatinib therapy after surgical resection.

The relationship between clinicopathological features were summarized in Table 2. The mitotic index exceeded $5 / 50 \mathrm{HPF}$ for the majority of male patients but only for the minority of female patients $(P=0.002)$, and it was positively related with tumor size $(P=0.005)$. Age was associated with tumor location $(P=0.017)$. For patients less than 60 years old, the commonest location were transverse and sigmoid colon. For patients more than 60 years old, the commonest location was sigmoid colon only.

Survival data of colonic GISTs were summarized in Table 3. Survival data of 48 patients were eventually 
Table 6: Comparison of predefined variables between colonic and gastric GISTs

\begin{tabular}{|l|l|l|l|}
\hline Characteristics & Colon $(\boldsymbol{n}=\mathbf{3 9})$ & Stomach $(\boldsymbol{n}=\mathbf{3 9})$ & $\boldsymbol{P}$ value \\
\hline Age & & & \\
\hline$\leq 60$ & 17 & 18 & 1.000 \\
\hline$>60$ & 22 & 21 & \\
\hline Gender & & & \\
\hline Male & 15 & 16 & 1.000 \\
\hline Female & 24 & 23 & \\
\hline Tumor size & & & \\
\hline$\leq 2 \mathrm{~cm}$ & 5 & 5 & 1.000 \\
\hline $2.1-5 \mathrm{~cm}$ & 9 & 9 & \\
\hline $5.1-10 \mathrm{~cm}$ & 17 & 17 & \\
\hline$>10 \mathrm{~cm}$ & 8 & 8 & \\
\hline Mitotic index & & & 1.000 \\
\hline$\leq 5$ & 21 & 21 & \\
\hline$>5$ & 18 & 18 & \\
\hline Adjuvant therapy & & 2 & 1.000 \\
\hline Yes & 2 & 37 & \\
\hline No & 37 & & \\
\hline
\end{tabular}

selected for analysis. The median follow-up time was 23.5 months (range from 3 to 149 months). Fifteen cases showed recurrence or metastasis, 18 patients suffered from GIST related deaths. The 1-, 3- and 5-year DSS was $85.0 \%, 66.0 \%$ and $61.6 \%$, respectively. The 1-, 3- and 5 -year DFS was $90.8 \%, 78.0 \%$ and $57.4 \%$, respectively. The DFS and DSS of colonic GISTs were shown in Figure 2 .

Prognostic factors for DFS and DSS were shown in Table 4. Mitotic index and NIH risk classification were associated with prognosis of colonic GISTs. However, only mitotic index was independent risk factor. The
DFS and DSS according to mitotic index and NIH risk classification were shown in Figure 3 and 4. NIH risk classification was not enrolled in logistic regression analysis, although it showed significant correlation with prognosis. Because no patients suffered from recurrence, metastasis or death in NIH risk category 1 and 2. When calculating log of odds ratio, the null frequency resulted in a computational error due to presence of logarithm of zero.

The clinicophathological features of 79 colonic GISTs were compared with 297 gastric GISTs in our center (Table 5). The results showed that the distribution of tumor size and NIH risk classification were significantly

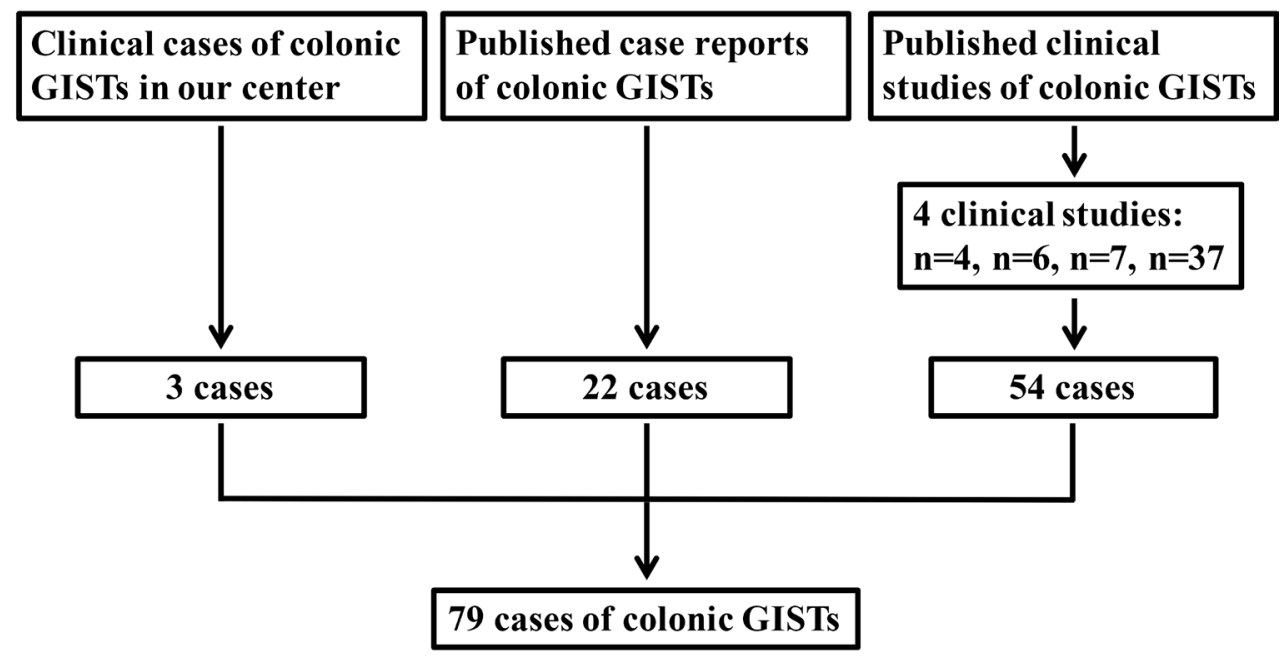

Figure 1: Schematic diagram regarding selection of colonic GISTs. 
different between colonic and gastric GISTs (both $P=$ 0.000). In order to compare the prognosis between colonic and gastric GISTs, the two groups were matched according to tumor size, mitotic index and imatinib treatment. The entire process was shown in Figure 5. Finally, 39 cases of colonic GISTs and 39 cases of gastric GISTs were selected. No intergroup difference was found in age, gender, tumor size, mitotic index and imatinib treatment (Table 6$)$. The DFS $(P=0.012)$ and DSS $(P=0.002)$ of colonic GISTs were significantly lower than that of gastric GISTs (56.0\% vs $85.7 \%$, 62.7\% vs 96.3\%).

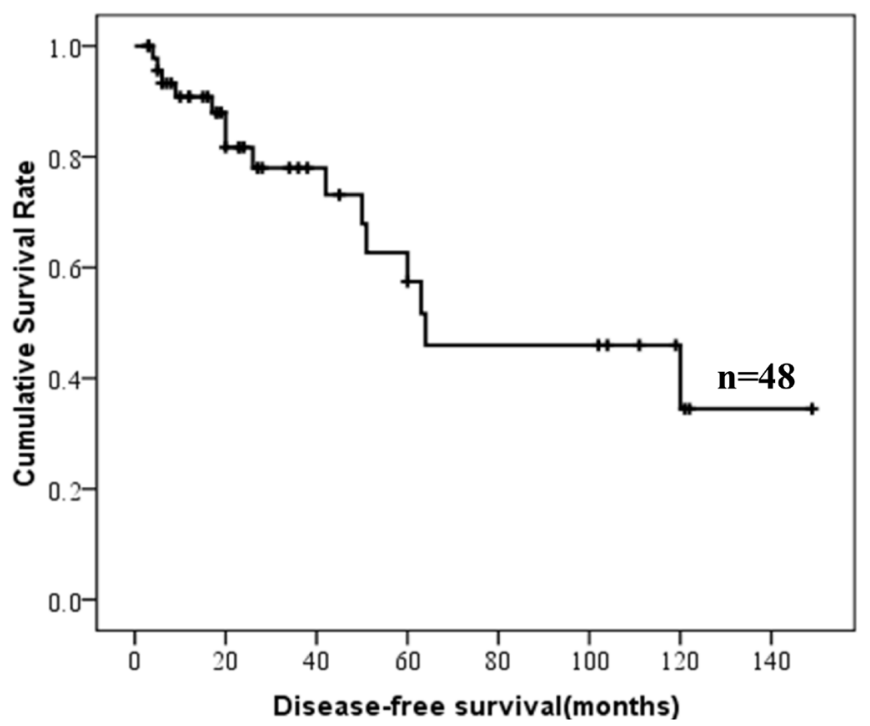

Figure 2: DFS and DSS of colonic GISTs.
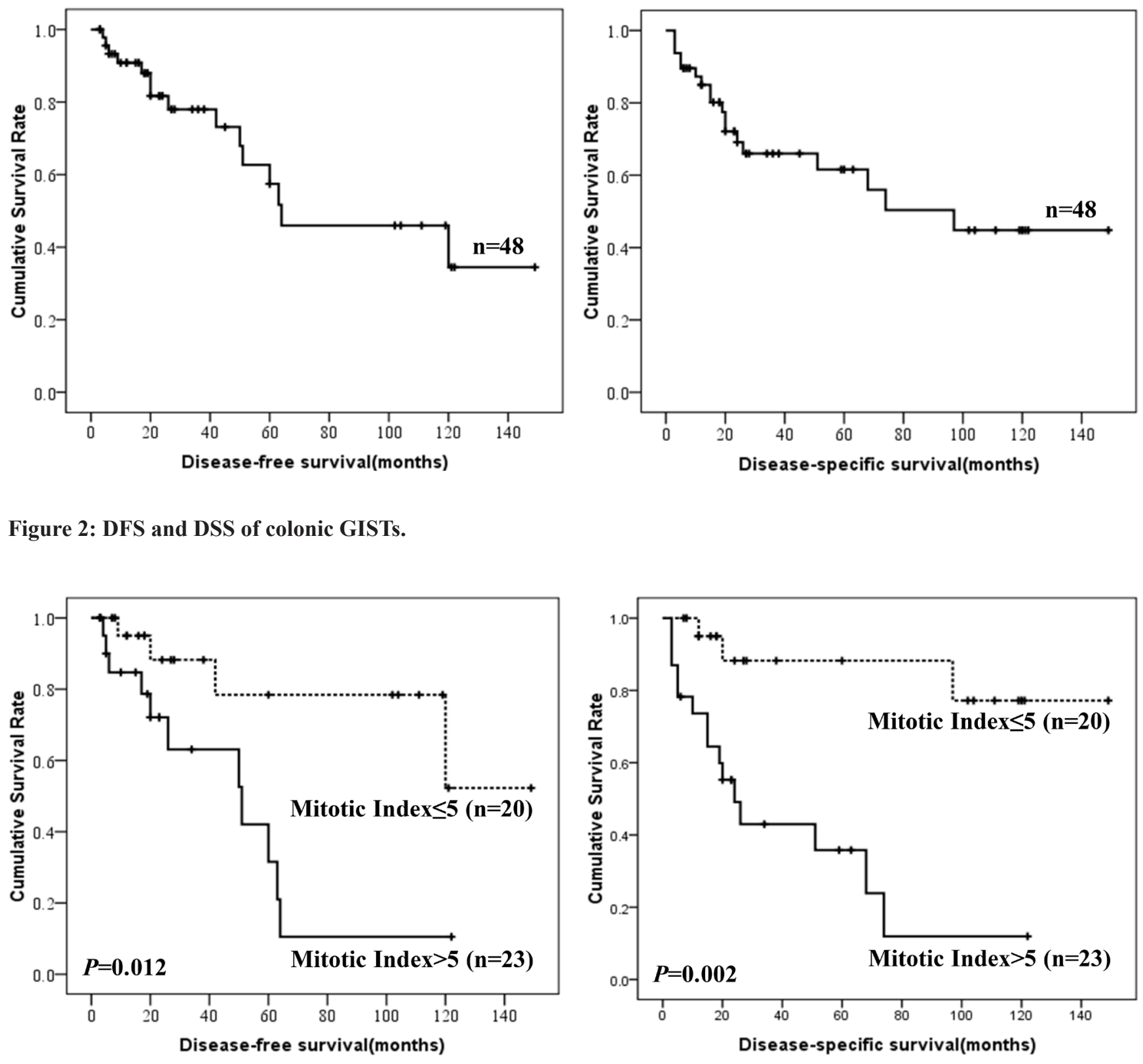
subset with limited data on the clinicopathological features and prognosis. Therefore, we evaluated 79 cases of colonic GISTs from our center and from literatures in MEDLINE. The present study represents the largest analysis of colonic GISTs.

The study containing 37 cases of colonic GISTs reported by Miettinen et al. [8] was the only one with a much larger number of patients. In the series, the

Figure 3: DFS and DSS of colonic GISTs by mitotic index. 
commonest site was sigmoid colon, followed by transverse colon, cecum, descending and ascending colon. In our present study, the commonest location was also sigmoid colon, and followed by transverse colon. However, the ratio of cecum, ascending and descending colon were almost equivalent. The distribution of GISTs may
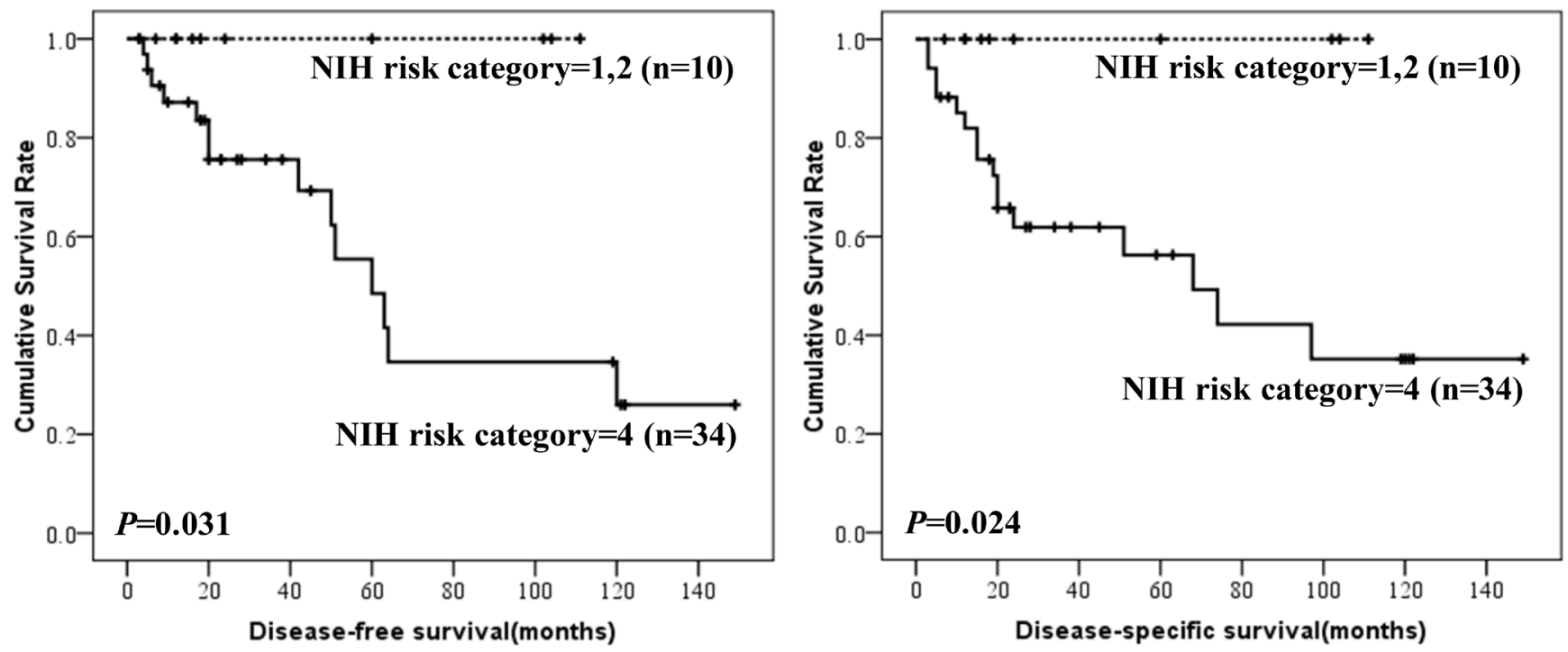

Figure 4: DFS and DSS of colonic GISTs by NIH risk category.

\begin{tabular}{|c|c|}
\hline $\begin{array}{c}\text { Colonic GISTs } \\
n=79\end{array}$ & $\begin{array}{c}\text { Gastric GISTs } \\
\mathbf{n}=\mathbf{2 9 7}\end{array}$ \\
\hline$\downarrow$ & $\downarrow$ \\
\hline \multicolumn{2}{|c|}{$\begin{array}{l}\text { Exclusion criteria: } \\
\text { 1. Not receive R0 resection } \\
\text { 2. With tumor rupture during operation } \\
\text { 3. Accompanied with distant metastasis } \\
\text { 4. Accompanied with GIST in other locations } \\
\text { 5. Accompanied with other malignant tumors } \\
\text { 6. With neoadjuvant imatinib therapy } \\
\text { 7. Without follow up data. }\end{array}$} \\
\hline & \\
\hline \multicolumn{2}{|c|}{$\begin{array}{l}\text { Matched according to the following parameters: } \\
\text { 1. Tumor size: } 0-2 \mathrm{~cm}, 2.1-5 \mathrm{~cm}, 5.1-10 \mathrm{~cm},>10 \mathrm{~cm} \\
\text { 2. Mitotic index: } \leq 5 / 50 \mathrm{HPF},>5 / 50 \mathrm{HPF} \\
\text { 3. Adjuvant imatinib therapy: yes, no }\end{array}$} \\
\hline$\downarrow$ & \\
\hline $\begin{array}{c}\text { Colonic GISTs } \\
\qquad \mathbf{n}=39\end{array}$ & $\begin{array}{c}\text { Gastric GISTs } \\
\mathbf{n}=39\end{array}$ \\
\hline
\end{tabular}

Figure 5: Flow chart of match strategy between colonic and gastric GISTs. 
be attributed to the distribution of ICCs in the colon. However, Hagger et al. reported that the highest density of ICC was at the myenteric plexus of the transverse colon, not the sigmoid colon [9]. Further, we found that the distribution of colonic GISTs was correlated with age of patients. For patients less than 60 years old, the commonest location were transverse and sigmoid colon. For patients more than 60 years old, the commonest location was sigmoid colon only. This may be attributed to the decline of ICC number in the colon with age at a rate of $13 \%$ per decade reported by Gomez-Pinilla et al. [10]. They also found that volume of ICC networks decreased more quickly with age in the ascending colon than that in the sigmoid colon. Although the distribution of colonic GISTs in our present study could not fully elucidated by the above studies, they provide clues for the investigation of distribution of colonic GISTs.

The surgical treatment of GISTs is radical resection of the primary tumor with negative microscopic margins. It is well known that lymph node involvement are rare [11], and lymphadenectomy or mesorectal excision is unnecessary. An appropriate segmental en bloc resection is enough for colonic GISTs only if adjacent organs are involved [12]. However, 3 of 17 patients (17.6\%) had lymph node metastasis in our present study, which was apparently higher than the previous report. Although the incidence of lymph node metastasis was relatively low, necessity of lymphadenectomy may need careful consideration in the treatment of colonic GISTs.

Even with surgical resection, there is a high risk of recurrence and metastasis. Distant metastases are the most frequent treatment failure for colorectal GISTs and are associated with poor prognosis. The most common site of metastasis in colorectal GISTs is liver, followed by peritoneum. Other locations include pleura, lung, bone and retroperitoneum [13]. In our present study, 9 patients suffered liver metastasis and 7 patients suffered peritoneal metastasis. Whereas GISTs predominantly metastasis to liver and leiomyosarcomas mainly spread to lung [14]. This may assistant in the differential diagnosis of the two tumors.

It was reported that approximately $10-30 \%$ of GISTs are regarded as clinically malignant [15], and tumor size and mitotic index are valuable predictors for evaluating malignant potential of GISTs [16]. In the present study, mitotic index more than 5/50HPF and high risk category were associated with poorer prognosis. Tumor location is also a critical risk factor for recurrence after radical surgical resection [17]. However, the modified NIH risk classification system only distinguishes gastric from nongastric tumors. The prognostic features of colonic GISTs are unclear. Considering different distribution of tumor size and NIH risk category between colonic and gastric GISTs, patients were matched in order to compare the prognosis. The survival analysis showed that the DFS and DSS of colonic GISTs were significantly lower than gastric GISTs. It was reported that non-gastric GISTs have similar risk for tumor recurrence [18]. However, the survival of colonic GISTs were not compared with that of duodenum, small intestine or rectum, due to the limited sample size of GISTs in these locations in our center.

There are some limitations of the present study. First, the present study is a retrospective analysis and lacks systematic prospective data. Therefore, completeness of the data is limited. Second, the sample size of colonic GISTs was not large enough, which will result in sampling error. Third, due to the limited sample size of duodenum, small intestine or rectum GISTs in our center, we could not
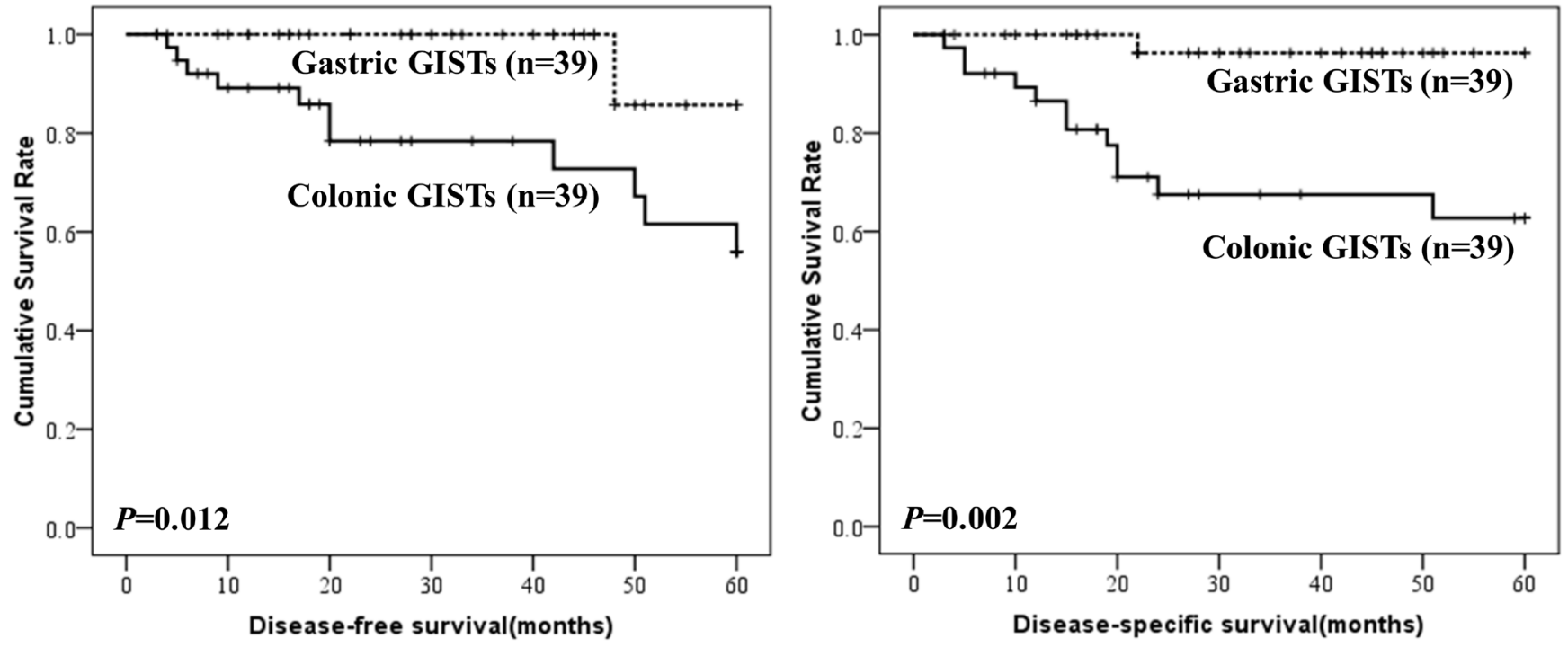

Figure 6: Comparison of DFS and DSS between colonic and gastric GISTs. 
compare the clinicopathological features and prognosis of colonic with non-gastric GISTs.

\section{CONCLUSIONS}

The commonest location for colonic GISTs was sigmoid colon, followed by transverse colon. Most colonic GISTs are high risk category. Mitotic index was the unique independent predictor for the prognosis of colonic GISTs. Colonic GISTs differ significantly from gastric GISTs in respect to clinicopathological features. The prognosis of colonic GISTs was worse than that of gastric GISTs.

\section{PATIENTS AND METHODS}

GISTs cases of the colon were from our department and in addition from the literature. From May 2010 to March 2015, 3 cases of colonic GISTs were diagnosed and received treatment in our department. Literature search of MEDLINNE was performed for all articles in English published from 2000 through 2015. MEDLINNE search resulted in 21 case reports [19-39] including 22 patients and 4 case series $[8,40-42]$ including 54 cases. To this end, a total of 79 colonic GISTs patients were identified (Figure 1). In addition, the clinicopathological characteristics and prognosis of 297 cases of gastric GISTs were analyzed and compared with colonic GISTs. This study was approved by the Ethics Committee of Xijing Hospital, and written informed consent was obtained from the three patients in our center.

Clinicopathological data including age, gender, accompanied tumor, symptoms, location, tumor size, surgical intervention, histological type, lymph node involvement, mitotic index, immunohistochemical features, mutational status, NIH risk category, adjuvant therapy, tumor recurrence or metastasis and survival data were recorded from hospital medical records or extracted from published reports and studies. The tumors were categorized into very low, low, intermediate and high risk groups according to the modified NIH risk classification criteria [43]. For survival analysis, the exclusion criteria were listed as follows: 1 . not receive $\mathrm{R} 0$ resection, 2 . with tumor rupture during operation, 3. accompanied with distant metastasis, 4. accompanied with GIST in other locations, 5. accompanied with other malignant tumors, 6. with neoadjuvant imatinib therapy, 7 . without follow up data. Due to data acquisition, completeness of data is limited.

Data were processed using SPSS 16.0 for Windows (SPSS Inc., Chicago, IL, USA). Numerical variables were expressed as the mean \pm SD unless otherwise stated. Discrete variables were analyzed using the Chi-square test or Fisher's exact test. Significant predictors for survival identified by univariate analysis were assessed by multivariate analysis using the logistic regression analysis. Evaluation for disease-free-survival (DFS) and disease-specific-survival (DSS) were obtained by the Kaplan-Meier method. The P value was considered to be statistically significant at the 5\% level.

\section{ACKNOWLEDGMENTS}

This study was supported in part by grants from the National Natural Scientific Foundation of China [NO. 31100643, 31570907, 81572306, 81502403, XJZT12Z03].

\section{CONFLICTS OF INTEREST}

There are no financial or other relations that could lead to a conflict of interest.

\section{REFERENCES}

1. Grignol VP and Termuhlen PM. Gastrointestinal stromal tumor surgery and adjuvant therapy. Surg Clin North Am. 2011; 91:1079-1087.

2. Hirota S, Isozaki K, Moriyama $\mathrm{Y}$, Hashimoto K, Nishida T, Ishiguro S, Kawano K, Hanada M, Kurata A, Takeda M, Muhammad Tunio G, Matsuzawa Y, Kanakura Y, Shinomura Y and Kitamura Y. Gain-of-function mutations of c-kit in human gastrointestinal stromal tumors. Science (New York, NY). 1998; 279:577-580.

3. Miettinen M and Lasota J. Gastrointestinal stromal tumors: review on morphology, molecular pathology, prognosis, and differential diagnosis. Archives of pathology \& laboratory medicine. 2006; 130:1466-1478.

4. Agaimy A, Wang LM, Eck M, Haller F and Chetty R. Loss of DOG-1 expression associated with shift from spindled to epithelioid morphology in gastric gastrointestinal stromal tumors with KIT and platelet-derived growth factor receptor alpha mutations. Annals of diagnostic pathology. 2013; 17:187-191.

5. Yang J, Feng F, Li M, Sun L, Hong L, Cai L, Wang W, $\mathrm{Xu} \mathrm{G}$ and Zhang H. Surgical resection should be taken into consideration for the treatment of small gastric gastrointestinal stromal tumors. World journal of surgical oncology. 2013; 11:273.

6. Miettinen M and Lasota J. Gastrointestinal stromal tumorsdefinition, clinical, histological, immunohistochemical, and molecular genetic features and differential diagnosis. Virchows Archiv. 2001; 438:1-12.

7. Edge SB and Compton CC. The American Joint Committee on Cancer: the 7 th edition of the AJCC cancer staging manual and the future of TNM. Annals of surgical oncology. 2010; 17:1471-1474.

8. Miettinen M, Sarlomo-Rikala M, Sobin LH and Lasota J. Gastrointestinal stromal tumors and leiomyosarcomas in the colon: a clinicopathologic, immunohistochemical, and molecular genetic study of 44 cases. The American journal of surgical pathology. 2000; 24:1339-1352. 
9. Hagger R, Gharaie S, Finlayson C and Kumar D. Regional and transmural density of interstitial cells of Cajal in human colon and rectum. The American journal of physiology. 1998; 275:G1309-1316.

10. Gomez-Pinilla PJ, Gibbons SJ, Sarr MG, Kendrick ML, Shen KR, Cima RR, Dozois EJ, Larson DW, Ordog T, Pozo MJ and Farrugia G. Changes in interstitial cells of cajal with age in the human stomach and colon. Neurogastroenterology and motility. 2011; 23:36-44.

11. Joensuu H, Hohenberger P and Corless CL. Gastrointestinal stromal tumour. Lancet (London, England). 2013; 382:973983.

12. Amato A. Colorectal gastrointestinal stromal tumor. Techniques in coloproctology. 2010; 14 Suppl 1:S91-95.

13. Reddy RM and Fleshman JW. Colorectal gastrointestinal stromal tumors: a brief review. Clinics in colon and rectal surgery. 2006; 19:69-77.

14. Plaat BE, Hollema H, Molenaar WM, Torn Broers GH, Pijpe J, Mastik MF, Hoekstra HJ, van den Berg E, Scheper RJ and van der Graaf WT. Soft tissue leiomyosarcomas and malignant gastrointestinal stromal tumors: differences in clinical outcome and expression of multidrug resistance proteins. Journal of clinical oncology. 2000; 18:3211-3220.

15. Huang RX, Xiang $\mathrm{P}$ and Huang C. Gastrointestinal stromal tumors: current translational research and management modalities. European review for medical and pharmacological sciences. 2014; 18:3076-3085.

16. Dematteo RP, Gold JS, Saran L, Gonen M, Liau KH, Maki RG, Singer S, Besmer P, Brennan MF and Antonescu CR. Tumor mitotic rate, size, and location independently predict recurrence after resection of primary gastrointestinal stromal tumor (GIST). Cancer. 2008; 112:608-615.

17. Rutkowski P, Nowecki ZI, Michej W, Debiec-Rychter M, Wozniak A, Limon J, Siedlecki J, Grzesiakowska U, Kakol M, Osuch C, Polkowski M, Gluszek S, Zurawski Z and Ruka W. Risk criteria and prognostic factors for predicting recurrences after resection of primary gastrointestinal stromal tumor. Annals of surgical oncology. 2007; 14:20182027.

18. Joensuu H, Vehtari A, Riihimaki J, Nishida T, Steigen SE, Brabec P, Plank L, Nilsson B, Cirilli C, Braconi C, Bordoni A, Magnusson MK, Linke Z, Sufliarsky J, Federico M, Jonasson JG, et al. Risk of recurrence of gastrointestinal stromal tumour after surgery: an analysis of pooled population-based cohorts. The Lancet Oncology. 2012; 13:265-274.

19. Gupta S, Punia RS and Kaushik R. Gastrointestinal stromal tumour of the colon presenting with intestinal obstruction. Indian journal of cancer. 2004; 41:175-177.

20. Rana R, Nikolaidis P and Miller F. Calcified gastrointestinal stromal tumor of the sigmoid colon mimicking inspissated barium on CT. AJR American journal of roentgenology. 2006; 187:W322-323.

21. Dimitroulopoulos DA, Arnogiannaki NA, Korkolis DP,
Xinopoulos DN, Paraskevas ET and Fotopoulou AP. Synchronous occurrence of colorectal adenocarcinoma and colonic gastrointestinal stromal tumor. Southern medical journal. 2009; 102:221-222.

22. Masoodi I, Chalkoo M, Rashid A and Wani IA. Extra luminal colonic gastrointestinal stromal tumor: a case report. Cases journal. 2009; 2:7525.

23. Macias-Garcia F, Parada P, Martinez-Lesquereux L, Pintos E, Fraga M and Dominguez-Munoz JE. Gastrointestinal stromal tumors (GISTs) of the colon. Revista espanola de enfermedades digestivas. 2010; 102:388-390.

24. Pandey S, Agarwal T, Jain V and Mishra S. Malignant CD 117 negative colonic GIST - a case report. International journal of surgery (London, England). 2010; 8:395-397.

25. Van Rompuy AS, Lannoo M, D'Hondt M, D'Hoore A and Geboes K. Gastrointestinal stromal tumour (GIST) arising in a colonic duplication cyst: case report. Colorectal disease. 2010; $12: 1053$.

26. Hwangbo Y, Jang JY, Kim HJ, Kim YW, Park SD, Shim J, Dong SH, Kim HJ, Kim BH, Chang YW and Chang R. Spontaneous rupture of a sigmoid colon gastrointestinal stromal tumor manifesting as pneumoretroperitoneum with localized peritonitis: report of a case. Surgery today. 2011; 41:1085-1090.

27. Troupis TG, Chatzikokolis S, Michalinos A, Sarakinos A, Kotsopoulos P, Patsea H, Kotsinas A, Evangelou K and Gorgoulis VG. GIST mimicking an hyperplastic polyp of descending colon. Annali italiani di chirurgia. 2011; 82:141-146.

28. Okur A, Oguz A, Karadeniz C, Pinarli FG, Ozen O and Ekinci O. High-risk CD117-positive gastrointestinal stromal tumor of the colon in a 12-year-old girl: adjuvant treatment with imatinib mesylate. Tumori. 2012; 98:59e-62e.

29. Okamura T, Kanda T, Hirota S, Nishimura A, Kawahara $\mathrm{M}$ and Nikkuni K. Imatinib therapy for a patient with metastasis of colonic gastrointestinal stromal tumor: report of a case. Clinical journal of gastroenterology. 2013; 6:116121.

30. Ratan SK, Goel G, Sobti P, Khurana N, Mathur M, Sinha SK and Aggarwal SK. Colonic gastrointestinal stromal tumour presenting as intussusception. APSP journal of case reports. 2013; 4:19.

31. Accarpio F, Cerbone L, Sibio S, Framarino M, Biacchi D, Borrini F, Cardi M, Rossi S, Toffolatti L, Iafrate F, Laghi A, Di Giorgio A and Sammartino P. Synchronous sporadic gastrointestinal stromal tumors (GISTs) of the colon. Endoscopy. 2014; 46 Suppl 1 UCTN:E252-253.

32. Badshah MB, Riaz H, Korsten MA, Dhala A, Park YH, Abadi M and Badshah MB. Gastro-intestinal stromal tumor (GIST) complicating a colonic interposition: a novel case report. BMC research notes. 2014; 7:604.

33. Kurokawa S, Morikawa A, Kubo T and Morita T. TorricelliBernoulli sign in a large intestine gastrointestinal stromal tumor. Internal medicine (Tokyo, Japan). 2014; 53:2547. 
34. Niazi AK, Kaley K and Saif MW. Gastrointestinal stromal tumor of colon: a case report and review of literature. Anticancer research. 2014; 34:2547-2550.

35. Sumi T, Katsumata K, Shibuya M, Katayanagi S, Iwasaki K, Kasuya K, Serizawa H, Shimazu M and Tsuchida A. A case of a gastrointestinal stromal tumor with skeinoid fibers of the sigmoid colon. Case reports in gastroenterology. 2014; 8:257-263.

36. Ueno G, Maeda T, Arima R, Oka H and Hirota S. A planar gastrointestinal stromal tumor replacing the proper muscle layer causing fecaloma and perforation in the sigmoid colon: a case report and literature review. Clinical journal of gastroenterology. 2014; 7:328-332.

37. Wang YP, Li Y and Song C. Metachronous multiple gastrointestinal stromal tumors and adenocarcinoma of the colon: A case report. Oncology letters. 2014; 8:1123-1126.

38. Yamashita D, Usami Y, Toyosawa S, Hirota S and Imai Y. A case of diffuse infiltrating gastrointestinal stromal tumor of sigmoid colon with perforation. Pathology international. 2014; 64:34-38

39. Palaghia M, Mihai C, Danciu M, Tarcoveanu E, Crumpei $\mathrm{F}$ and Prelipcean CC. LIVER METASTASIS OF A GASTROINTESTINAL STROMAL TUMOR OF LARGE BOWEL: CASE REPORT. Revista medico-chirurgicala a Societatii de Medici si Naturalisti din Iasi. 2015; 119:395400 .
40. Hassan I, You YN, Dozois EJ, Shayyan R, Smyrk TC, Okuno $\mathrm{SH}$ and Donohue JH. Clinical, pathologic, and immunohistochemical characteristics of gastrointestinal stromal tumors of the colon and rectum: implications for surgical management and adjuvant therapies. Diseases of the colon and rectum. 2006; 49:609-615.

41. Agaimy A, Wunsch PH, Dirnhofer S, Bihl MP, Terracciano LM and Tornillo L. Microscopic gastrointestinal stromal tumors in esophageal and intestinal surgical resection specimens: a clinicopathologic, immunohistochemical, and molecular study of 19 lesions. The American journal of surgical pathology. 2008; 32:867-873.

42. Chen CW, Wu CC, Hsiao CW, Fang FC, Lee TY, Che FC, Tsai WC and Jao SW. Surgical management and clinical outcome of gastrointestinal stromal tumor of the colon and rectum. Zeitschrift fur Gastroenterologie. 2008; 46:760765 .

43. Joensuu H. Risk stratification of patients diagnosed with gastrointestinal stromal tumor. Hum Pathol. 2008; 39:14111419. 